\title{
Serum EA-IgA and D-dimer, but not VCA-lgA, are associated with prognosis in patients with nasopharyngeal carcinoma: a meta-analysis
}

Tianhao Liang ${ }^{\dagger}$, Weixing Liu ${ }^{\dagger}$, Junyang Xie ${ }^{\dagger}$, Yiyan Wang, Gui Chen, Wenjing Liao, Lijuan Song and Xiaowen Zhang ${ }^{*}$ (D)

\begin{abstract}
Background: Patients with nasopharyngeal cancer (NPC) differ in prognosis, even at the same stage; therefore, new biomarkers are urgently required to identify early-stage NPC patients at high risk of poor prognosis. Although EpsteinBarr virus (EBV) DNA has been used for prognosis, the value of many other biomarkers expressed during the infection cycle of EBV remains unclarified. This study aimed to evaluate the prognostic potential of EA-IgA, VCA-IgA and D-dimer in patients with NPC.

Methods: Electronic databases, including PubMed, Embase and Web of Science, were searched up to February 1, 2021. Pooled data were extracted from studies that evaluated the relationship between NPC and overall survival (OS), distant metastasis-free survival (DMFS) or disease-free survival (DFS) and then were subjected to a meta-analysis.

Results: Nine studies with 5729 patients were included in this meta-analysis. In patients with NPC, EA-IgA levels significantly predicted OS ( $H R=1.63,95 \% \mathrm{Cl} 1.07-2.48)$. D-Dimer levels significantly predicted OS $(H R=1.75,95 \%$ $\mathrm{Cl} 1.24-2.47)$ and DMFS ( $H R=1.91,95 \% \mathrm{Cl} 1.31-2.79)$. However, high levels of VCA-IgA were not associated with OS $(\mathrm{HR}=1.24,95 \% \mathrm{Cl} 0.95-1.60)$, DMFS ( $\mathrm{HR}=1.41,95 \% \mathrm{Cl} 0.92-2.17)$ or $\mathrm{DFS}(\mathrm{HR}=2.39,95 \% \mathrm{Cl} 0.78-7.26)$.
\end{abstract}

Conclusions: The present findings reveal that EA-IgA and D-dimer, but not VCA-IgA, can be used as prognostic biomarkers in NPC.

Keywords: EA-IgA, D-Dimer, VCA-IgA, Nasopharyngeal carcinoma, Prognosis, Meta-analysis

\section{Background}

Nasopharyngeal carcinoma (NPC) is a common epithelial carcinoma arising from the nasopharyngeal mucosal lining. In comparison with other cancers, NPC

\footnotetext{
*Correspondence: zhangxiaowen@gzhmu.edu.cn

†Tianhao Liang, Weixing Liu and Junyang Xie-First authors State Key Laboratory of Respiratory Disease, Department

of Otolaryngology-Head and Neck Surgery, First Affiliated Hospital, Guangzhou Medical University, \#151 Yanjiang Road, Guangzhou 510120,

Guangdong, People's Republic of China
}

is characterized by an unbalanced global geographic distribution and a high incidence in East and Southeast Asia [1].

Despite improvements in treatment options, patients with advanced-stage NPC still have a poor prognosis. As early-stage NPC exhibits non-specific signs and symptoms, most patients present with an advanced stage of NPC at diagnosis. Recurrence and distant metastasis represent the leading causes of NPC-related death [2]. To date, the diagnosis and prognosis of NPC are determined mainly on the basis of the American Joint Committee

(c) The Author(s) 2021. This article is licensed under a Creative Commons Attribution 4.0 International License, which permits use, sharing, adaptation, distribution and reproduction in any medium or format, as long as you give appropriate credit to the original author(s) and the source, provide a link to the Creative Commons licence, and indicate if changes were made. The images or other third party material in this article are included in the article's Creative Commons licence, unless indicated otherwise in a credit line to the material. If material is not included in the article's Creative Commons licence and your intended use is not permitted by statutory regulation or exceeds the permitted use, you will need to obtain permission directly from the copyright holder. To view a copy of this licence, visit http://creativeco mmons.org/licenses/by/4.0/. The Creative Commons Public Domain Dedication waiver (http://creativecommons.org/publicdomain/ zero/1.0/) applies to the data made available in this article, unless otherwise stated in a credit line to the data. 
on Cancer (AJCC) staging system [3]. However, patients with NPC differ in prognosis, even at the same stage [4]. Therefore, prognostic indicators with higher specificity and sensitivity remain to be discovered and applied to the diagnosis and individualized treatment of patients with NPC. In this context, there is an urgent need for new biomarkers to identify early-stage NPC patients at high risk of poor prognosis.

Accumulating evidence suggests that NPC is strongly associated with Epstein-Barr virus (EBV) infection [5]. EBV-DNA is currently recognized as a prognostic indicator of nasopharyngeal carcinoma [6, 7]. Many antibodies are expressed during the infection cycle of EBV; their use as prognostic markers for nasopharyngeal carcinoma remains controversial. The protein fragment $\mathrm{D}$-dimer is an important prognostic marker for other tumors, but its role in NPC has not been well clarified.

The value of anti-EBV IgA antibodies (e.g., EA-IgA, VCA-IgA) and other EBV-related antibodies for NPC diagnosis has been reported [8]. Our previous work indicates that EBV-DNA and EBV-related antibodies have diagnostic value [9]. Further to our previous report, this meta-analysis was conducted to shed light on the prognostic value of these biomarkers in NPC patients through a literature search of published studies, data extraction, quality assessment and statistical processing.

\section{Methods}

The data in this meta-analysis were presented strictly in accordance with the PRISMA reporting guidelines [10].

\section{Data sources and literature search strategy}

Two independent investigators performed systematic searches of online databases, including PubMed, Embase, and Web of Science, for articles published up to February 1, 2021. The following search strategy was used: (nasopharyngeal and (cancer or tumor or carcinoma or neoplasm) and (EBV-DNA or 'Epstein Barr virus' or 'capsid antigen-IgA' or 'early antigen antibody' or 'nuclear antigen antibody' or 'BRLF1 transcription activator IgG' or EA-IgA or VCA-IgA or Rta-IgG or EBNA1-IgA or D-dimer) and (prognosis or survival or mortality)). The articles were first screened by title and abstract. Next, duplicate articles and those not published in English were eliminated. Finally, all extracted data from the selected articles were synthesized for analysis.

\section{Inclusion and exclusion criteria}

The inclusion criteria were as follows: (1) the serum antibody levels of biomarkers were determined using enzyme-linked immunosorbent assay; (2) the recorded data included biomarkers and survival outcomes such as overall survival (OS), disease-free survival (DFS), progression-free survival (PFS), metastasis-free survival (MFS), local-regional failure survival (LRFS), relapsefree survival (RFS), and distant metastasis-free survival (DMFS). Studies published as case reports, conference abstracts, correspondence, or reviews were excluded.

\section{Data extraction and quality assessment}

The data extracted from the articles included study characteristics (first author, publication year, country of origin, total number of patients, gender, and age); cut-off values of biomarkers, tumor-node-metastasis classification (TNM) stage, and treatment plan; survival outcomes (including OS, DFS, PFS, MFS, LRFS, RFS, and DMFS); and statistical evaluations, including hazard ratios (HR), 95\% confidence intervals (95\% CI), and $P$-values. The study quality was assessed independently by two investigators according to the Newcastle-Ottawa Scale (NOS) [11]. The NOS scores ranged from 0 to 9 (allocated as stars). Articles with six stars or more were evaluated as high quality. All dissenting opinions were discussed until a consensus was reached.

\section{Statistical analysis}

Review Manager (RevMan) [Computer program]. Version 5.4, The Cochrane Collaboration, 2020 was used for data analysis. HR and $95 \% \mathrm{CI}$ were used to assess the prognostic values of independent biomarkers. The survival data were extracted by Engauge Digitizer 4.1 as KaplanMeier curves [12]. The inconsistency index $\left(I^{2}\right)$ was used to estimate the heterogeneity of individual studies, which facilitated generation of the pooled estimates. When heterogeneity across the studies was present $\left(I^{2}>50 \%\right)$, the random-effect model was selected; otherwise, the fixed-effect model was used. Sensitivity analysis was performed by deleting each included study in turn to explore the source of heterogeneity. The funnel plot, Begg's bias test, and Egger's test were applied to identify potential publication bias. $P<0.05$ was considered statistically significant.

\section{Results}

\section{Article search and study quality}

A total of 2195 studies were identified from Embase $(\mathrm{n}=1077)$ and PubMed $(\mathrm{n}=1118) ; 564$ studies were excluded due to duplication. Nine studies, comprising 5729 patients with NPC, were eligible for this meta-analysis [13-22]. One study was rejected due to lack of confidence interval data [19]. Figure 1 shows a flowchart of the study selection process. Table 1 shows the major characteristics and detailed NOS scores of the included studies. All included studies were retrospective. 

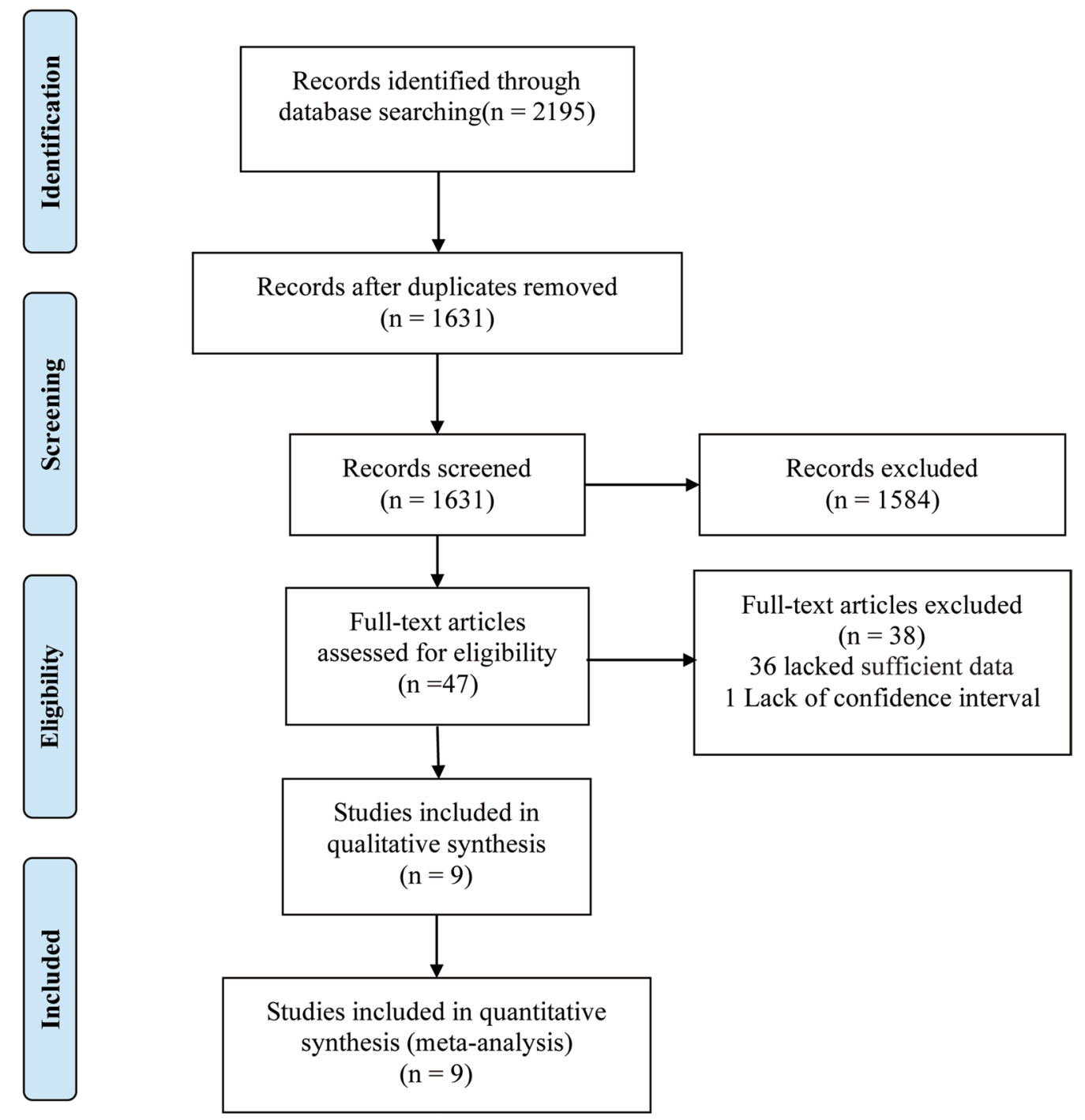

Fig. 1 Flowchart of the study selection process

\section{EA-IgA levels and survival outcome}

Six articles focused on the association between EAIgA and OS. The meta-analysis found that high levels of EA-IgA predicted a poor prognosis with low OS $(\mathrm{HR}=1.63,95 \% \mathrm{CI} 1.07-2.48)$ with the random-effect model $\left(I^{2}>50 \%\right)$. High levels of EA-IgA did not correlate with DMFS $(\mathrm{HR}=1.34,95 \%$ CI $0.96-1.85)$ or DFS (HR $=1.83,95 \%$ CI 0.54-6.21) in patients with NPC (Fig. 2). Results of the meta-analysis also showed that patients with high EA-IgA levels had a greater probability of adverse survival outcomes than patients with low EA-IgA levels.

\section{VCA-IgA levels and survival outcome}

Eight articles focused on the association between VCA-IgA and OS. The random-effect model was used for OS $\left(I^{2}=52 \%\right)$, and the fixed-effect model was used for DMFS and DFS $\left(I^{2} \leq 50 \%\right)$. The pooled metaanalysis indicated that high levels of VCA-IgA were 


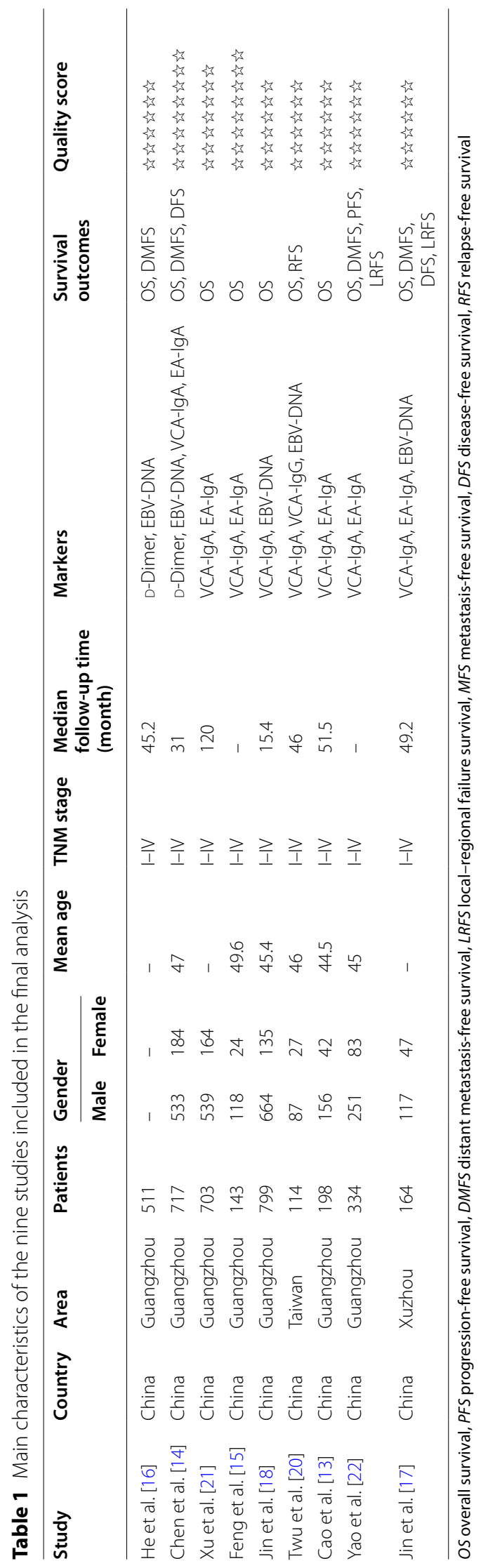




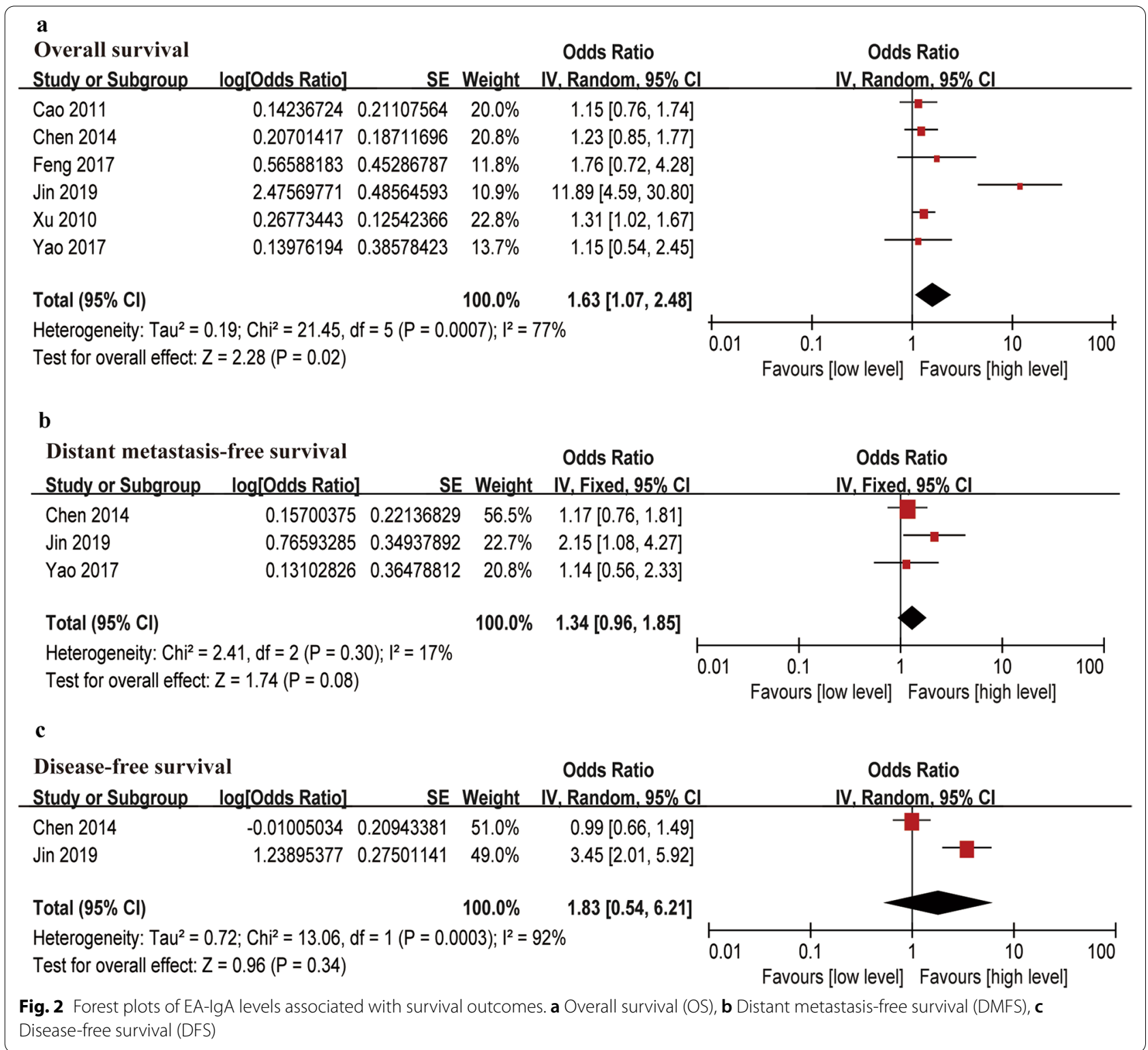

not associated with $\mathrm{OS}(\mathrm{HR}=1.24,95 \%$ CI $0.95-$ 1.60), DMFS (HR $=1.41,95 \%$ CI $0.92-2.17)$ or DFS $(\mathrm{HR}=2.39,95 \% \mathrm{CI} 0.78-7.26)$ in patients with NPC (Fig. 3).

\section{D-Dimer levels and survival outcome}

Two articles focused on the association between D-dimer and OS. By using the fixed-effect model $\left(I^{2} \leq 50 \%\right)$, the pooled meta-analysis indicated that high levels of D-dimer in NPC patients predicted a poor prognosis with low OS (HR $=1.75$, 95\% CI 1.24-2.47) and low DMFS $(\mathrm{HR}=1.91,95 \%$ CI 1.31-2.79) (Fig. 4). Patients with high D-dimer levels had a greater probability of poor survival outcomes.
Sensitivity analysis and publication bias

Sensitivity analysis suggested that the results of EA-IgA levels and OS were influenced by data from Jin et al. [17]. After the data from this article were removed, the heterogeneity reduced to $I^{2}<50 \%$. By using the fixedeffect model, we obtained consistent results: high levels of EA-IgA in NPC patients predicted a poor prognosis with low OS (HR $=1.75$, 95\% CI 1.24-2.47).

The funnel plot and Egger's test were used to investigate potential publication bias (Fig. 5). Using Egger's test, we found no evidence of bias in the meta-analysis that would otherwise explain the observed association between EA-IgA levels and OS $(P=0.365) . P>0.05$ indicates no significant publication bias. 


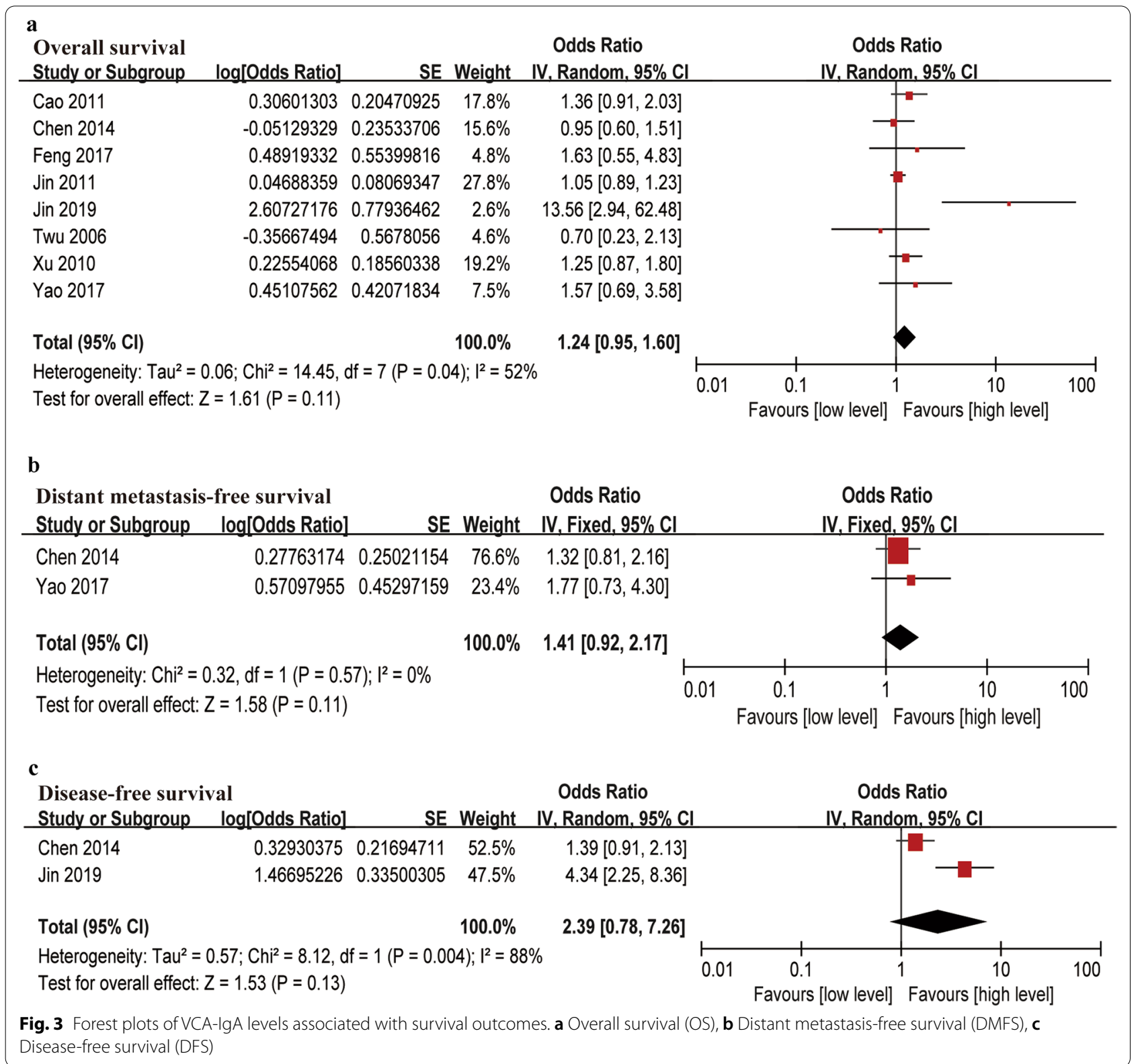

\section{Discussion}

The determination of plasma EBV-DNA levels is widely used to diagnose NPC and evaluate therapeutic efficacy $[23,24]$. The present study suggests that EBV-DNA levels could be used to predict the prognosis of NPC. The meta-analysis comprising nine studies with 5729 patients also explore the significance of other clinical indicators for predicting NPC prognosis. Our findings demonstrate that the levels of EA-IgA and D-dimer, but not VCA-IgA, are associated with survival endpoints.

Aggregate results reveal that EA-IgA can be used as an indicator of OS in patients with NPC. VCA-IgA does not seem to be an indicator of prognosis in patients with
NPC. D-Dimer may be a good indicator to predict OS and DMFS in patients with NPC. However, few studies have investigated D-dimer, so there is an urgent need to test more patient samples for $\mathrm{D}$-dimer to improve the evidence level of this biomarker. Furthermore, several studies indicated that biomarkers such as Rta-IgG, Zta-IgA, and EBNA1-IgA may also be prognostic indicators of NPC. Our meta-analysis did not assess these biomarkers due to the limited number of patients included in published prognostic studies.

Recent studies in NPC patients have identified antibodies against EBV antigens, including early antigen (EA), viral capsid antigen (VCA) and Epstein-Barr 


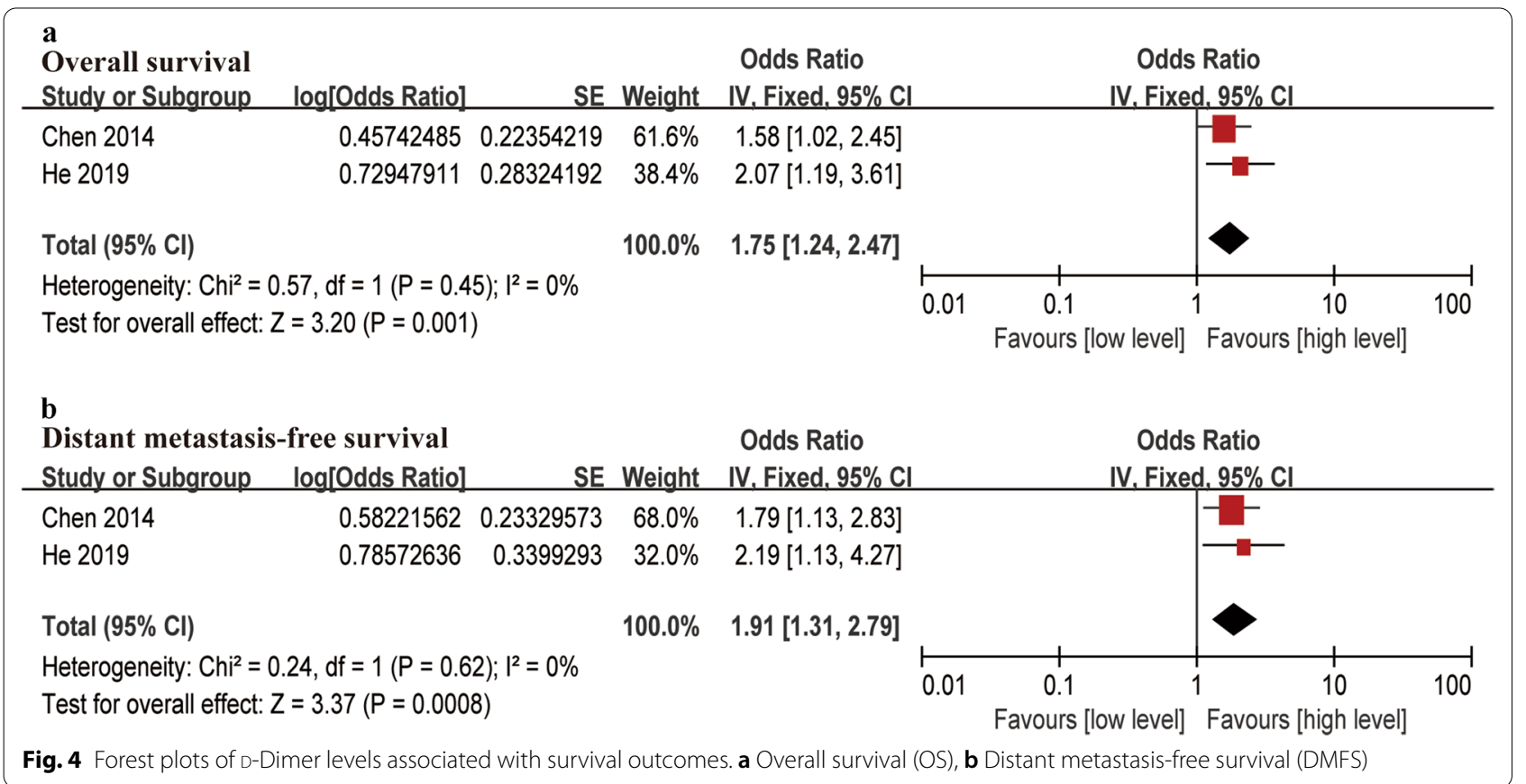

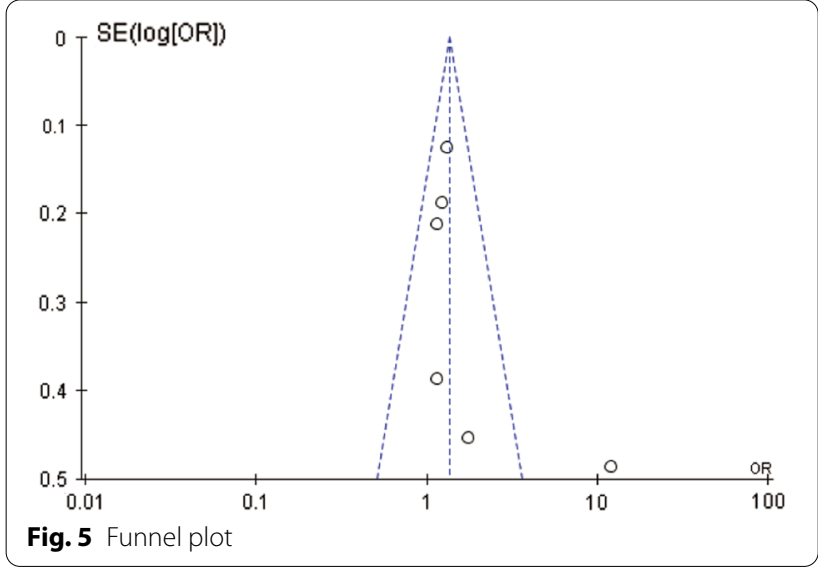

virus nuclear antigen 1 (EBNA1) [25]. When EBV enters the lytic cycle, Rta and Zta are encoded and then EA is encoded [26]. At the end of the EBV proliferation cycle, VCA is expressed. During the cycle of EBV proliferation, expression of these antigens induces a strong antibody response in patients with NPC [27]. The detection of EBV infection by measuring these antibody expression levels allows diagnosis and prognosis prediction of NPC. These antibodies may be detected at any period in clinical practice. Therefore, detection of these antibodies can improve the accuracy of prediction and guide clinicians to quickly adjust their treatment plans.

In recent years, the fibrinolytic system has attracted attention as a possible regulator of cancer progression
$[28,29]$. Plasma D-dimer has been used to evaluate the prognosis of various cancers, such as NPC, small-cell lung cancer [30] and gastrointestinal cancer [31]. The survival outcomes related to D-dimer in non-NPC cancers are similar to our meta-analysis results.

Prediction of NPC prognosis should be based on the patient's condition. Timely adjustments of treatment plans are expected to improve the prognosis and prolong the survival time of patients with NPC. Data from multiple antibody assays can improve prediction accuracy. Therefore, future research should aim to improve the combination of biomarkers used for prognosis prediction in patients with NPC.

Previously, EBV-DNA and other blood markers (such as LMP1) have been mainly used individually as prognostic indicators of NPC [32,33], which lacks accuracy. We speculate that combining multiple biomarkers can improve the accuracy of prognosis predictions, but this requires validation in future studies. Because most research has previously focused on EBV-DNA, our present study investigated the prognostic values of other indicators for NPC. Our previous study reported that EA-IgA can be used for the diagnosis of NPC [9]. Combined with data from this meta-analysis, we show that these biomarkers can be used as both diagnostic and prognostic indicators, because these indicators can be detected during the EBV infection cycle. This illustrates the importance of testing these indicators at different disease stages. 
There are some limitations to this study. First, all analyses were based on data extracted from nine published studies-the number of studies included in the final analysis was low, and all these studies were from China, which may increase the risk of selection and publication bias. Second, all nine studies were retrospective, which may increase heterogeneity. Third, expanding the analysis to other important antibodies expressed in response to the EBV infection cycle would be beneficial, although current data are limited. Finally, differences in follow-up duration and treatment regimens across the nine studies may also influence the results. A larger, prospective, randomized, multicenter clinical trial is required to confirm the prognostic potential of EA-IgA, D-dimer and VCA-IgA in NPC.

\section{Conclusions}

In conclusion, EA-IgA and D-dimer are important prognostic predictors in NPC. Combined detection of multiple indicators should improve the accuracy of prediction. Regular monitoring of relevant prognostic indicators will help clinicians make timely changes in treatment regimens and will improve patient survival. This research will inspire future prospective studies to validate whether panel detection of EA-IgA, D-dimer and EBV-DNA could more accurately predict the prognosis of NPC patients.

\begin{abstract}
Abbreviations
NPC: Nasopharyngeal carcinoma; EBV: Epstein-Barr virus; EA: Early antigen; VCA: Viral capsid antigen; EBNA1: Epstein-Barr virus nuclear antigen 1; TNM: Tumor-node-metastasis classification; Cl: Confidence interval; $P^{2}$ : Inconsistency index; HR: Hazard ratios; OS: Overall survival; DFS: Disease-free survival; PFS: Progression-free survival; MFS: Metastasis-free survival; LRFS: Localregional failure survival; RFS: Relapse-free survival; DMFS: Distant metastasisfree survival; NOS: Newcastle-Ottawa Scale.
\end{abstract}

\section{Acknowledgements}

Tianhao Liang, Weixing Liu and Junyang Xie are co-first author. We thank Liwen Bianji (Edanz) (www.liwenbianji.cn) for editing the language of a draft of this manuscript.

\section{Authors' contributions}

$T L, W L$ and $X Z$ conceived of and designed the study. XZ provided administrative support. TL and JX provided study materials or patients. TL, GC, and YW collected and assembled the data. TL, WL, JX, WL, and LS analyzed and interpreted the data. All authors wrote the manuscript, provided critical feedback and revised the manuscript. All authors read and approved the final manuscript.

\section{Funding}

Funding was received from the Upper Respiratory Disease Innovation and Transformation Platform Construction Project of the Guangdong Provincial and High-level Construction Project of Guangzhou Medical University.

\section{Availability of data and materials}

The datasets used during the current study are available from the corresponding author on reasonable request.

\section{Declarations}

Ethics approval and consent to participate

Not applicable.

\section{Consent for publication}

No identifying patient details are contained within this manuscript.

\section{Competing interests}

The authors declare no competing interests.

Received: 23 April 2021 Accepted: 21 June 2021

Published online: 30 June 2021

\section{References}

1. Chen YP, Chan ATC, Le QT, Blanchard P, Sun Y, Ma J. Nasopharyngeal carcinoma. Lancet. 2019;394:64-80. https://doi.org/10.1016/S0140-6736(19) 30956-0.

2. Lee HM, Okuda KS, González FE, Patel V. Current perspectives on nasopharyngeal carcinoma. Adv Exp Med Biol. 2019;1 164:11-34. https://doi. org/10.1007/978-3-030-22254-3_2.

3. Sun P, Chen C, Cheng YK, Zeng ZJ, Chen XL, Liu LZ, et al. Serologic biomarkers of Epstein-Barr virus correlate with TNM classification according to the seventh edition of the UICC/AJCC staging system for nasopharyngeal carcinoma. Eur Arch Otorhinolaryngol. 2014;271:2545-54. https:// doi.org/10.1007/s00405-013-2805-5.

4. Tang XR, Li YQ, Liang SB, Jiang W, Liu F, Ge WX, et al. Development and validation of a gene expression-based signature to predict distant metastasis in locoregionally advanced nasopharyngeal carcinoma: a retrospective, multicentre, cohort study. Lancet Oncol. 2018;19:382-93. https://doi. org/10.1016/S1470-2045(18)30080-9.

5. Tsao SW, Tsang CM, Lo KW. Epstein-Barr virus infection and nasopharyngeal carcinoma. Philos Trans R Soc Lond B Biol Sci. 2017. https://doi.org/ 10.1098/rstb.2016.0270.

6. Nilsson JS, Forslund O, Andersson FC, Lindstedt M, Greiff L. Intralesional EBV-DNA load as marker of prognosis for nasopharyngeal cancer. Sci Rep. 2019:9:15432. https://doi.org/10.1038/s41598-019-51767-9.

7. Wang WY, Twu CW, Chen HH, Jan JS, Jiang RS, Chao JY, et al. Plasma EBV DNA clearance rate as a novel prognostic marker for metastatic/recurrent nasopharyngeal carcinoma. Clin Cancer Res. 2010;16:1016-24. https:// doi.org/10.1158/1078-0432.CCR-09-2796.

8. Feng Y, Xia W, He G, Ke R, Liu L, Xie M, et al. Accuracy evaluation and comparison of 14 diagnostic markers for nasopharyngeal carcinoma: a meta-analysis. Front Oncol. 2020;10:1779. https://doi.org/10.3389/fonc. 2020.01779 .

9. Liu W, Chen G, Gong X, Wang Y, Zheng Y, Liao X, et al. The diagnostic value of EBV-DNA and EBV-related antibodies detection for nasopharyngeal carcinoma: a meta-analysis. Cancer Cell Int. 2021;21:164. https://doi. org/10.1186/s12935-021-01862-7.

10. Liberati A, Altman DG, Tetzlaff J, Mulrow C, Gøtzsche PC, loannidis JP, et al. The PRISMA statement for reporting systematic reviews and meta-analyses of studies that evaluate health care interventions: explanation and elaboration. PLoS Med. 2009;6: e1000100. https://doi.org/10.1371/journal. pmed. 1000100

11. Stang A. Critical evaluation of the Newcastle-Ottawa scale for the assessment of the quality of nonrandomized studies in meta-analyses. Eur J Epidemiol. 2010;25:603-5. https://doi.org/10.1007/s10654-010-9491-z.

12. Parmar MK, Torri V, Stewart L. Extracting summary statistics to perform meta-analyses of the published literature for survival endpoints. Stat Med. 1998;17:2815-34. https://doi.org/10.1002/(sici)1097-0258(19981230)17: 24\%3c2815::aid-sim110\%3e3.0.co;2-8.

13. Cao $X$, Luo RZ, He LR, Li Y, Lin WQ, Chen YF, et al. Prognosticators and risk grouping in patients with lung metastasis from nasopharyngeal carcinoma: a more accurate and appropriate assessment of prognosis. Radiat Oncol. 2011;6:104. https://doi.org/10.1186/1748-717X-6-104.

14. Chen WH, Tang LQ, Wang FW, Li CP, Tian XP, Huang XX, et al. Elevated levels of plasma D-dimer predict a worse outcome in patients with 
nasopharyngeal carcinoma. BMC Cancer. 2014;14:583. https://doi.org/10. 1186/1471-2407-14-583.

15. Feng $X$, Lin J, Xing S, Liu W, Zhang G. Higher IGFBP-1 to IGF-1 serum ratio predicts unfavourable survival in patients with nasopharyngeal carcinoma. BMC Cancer. 2017;17:90. https://doi.org/10.1186/ s12885-017-3068-0.

16. He SS, Wang Y, Wang CT, Zhu MY, Yang XL, Chen DM, et al. A combined marker based on plasma D-dimer and serum albumin levels in patients with nasopharyngeal carcinoma is associated with poor survival outcomes in a retrospective cohort study. J Cancer. 2019;10:3691-7. https:// doi.org/10.7150/jca.32387.

17. Jin PY, Zheng ZH, Lu HJ, Yan J, Zheng GH, Zheng YL, et al. Roles of $\beta$-catenin, TCF-4, and survivin in nasopharyngeal carcinoma: correlation with clinicopathological features and prognostic significance. Cancer Cell Int. 2019;19:48. https://doi.org/10.1186/s12935-019-0764-7.

18. Jin Y, Cai XY, Cai YC, Cao Y, Xia Q, Tan YT, et al. To build a prognostic score model containing indispensible tumour markers for metastatic nasopharyngeal carcinoma in an epidemic area. Eur J Cancer. 2012;48:882-8. https://doi.org/10.1016/j.ejca.2011.09.004.

19. Sun $P$, Chen $C$, Chen XL, Cheng YK, Zeng L, Zeng ZJ, et al. Proposal of a clinical typing system and generation of a prognostic model in patients with nasopharyngeal carcinoma from Southern China. J buon. 2014;19:474-83.

20. Twu CW, Wang WY, Liang WM, Jan JS, Jiang RS, Chao J, et al. Comparison of the prognostic impact of serum anti-EBV antibody and plasma EBV DNA assays in nasopharyngeal carcinoma. Int J Radiat Oncol Biol Phys. 2007;67:130-7. https://doi.org/10.1016/j.jijobp.2006.07.012.

21. Xu J, Wan XB, Huang XF, Chan KC, Hong MH, Wang LH, et al. Serologic antienzyme rate of Epstein-Barr virus DNase-specific neutralizing antibody segregates TNM classification in nasopharyngeal carcinoma. J Clin Oncol. 2010;28:5202-9. https://doi.org/10.1200/JCO.2009.25.6552.

22. Yao JJ, Lin L, Jin $Y N$, Wang $S Y$, Zhang WJ, Zhang F, et al. Prognostic value of serum Epstein-Barr virus antibodies in patients with nasopharyngeal carcinoma and undetectable pretreatment Epstein-Barr virus DNA. Cancer Sci. 2017;108:1640-7. https://doi.org/10.1111/cas.13296.

23. Lv J, Chen Y, Zhou G, Qi Z, Tan KRL, Wang H, et al. Liquid biopsy tracking during sequential chemo-radiotherapy identifies distinct prognostic phenotypes in nasopharyngeal carcinoma. Nat Commun. 2019;10:3941. https://doi.org/10.1038/s41467-019-11853-y.

24. Lu L, Li J, Zhao C, Xue W, Han F, Tao T, et al. Prognostic efficacy of combining tumor volume with Epstein-Barr virus DNA in patients treated with intensity-modulated radiotherapy for nasopharyngeal carcinoma. Oral Oncol. 2016;60:18-24. https://doi.org/10.1016/j.oraloncology.2016.06.013.

25. Fachiroh J, Paramita DK, Hariwiyanto B, Harijadi A, Dahlia HL, Indrasari SR, et al. Single-assay combination of Epstein-Barr Virus (EBV) EBNA1- and viral capsid antigen-p18-derived synthetic peptides for measuring anti-EBV immunoglobulin $\mathrm{G}(\mathrm{lgG})$ and IgA antibody levels in sera from nasopharyngeal carcinoma patients: options for field screening. J Clin Microbiol. 2006;44:1459-67. https://doi.org/10.1128/JCM.44.4.1459-1467. 2006.

26. Zhang G, Li Z, Zhou Q. Utility of serum EB virus Zta antibody in the diagnostic of nasopharyngeal carcinoma: evidences from 2126 cases and 15,644 controls. Front Oncol. 2019;9:1391. https://doi.org/10.3389/fonc. 2019.01391.

27. Liu Y, Huang Q, Liu W, Liu Q, Jia W, Chang E, et al. Establishment of VCA and EBNA1 IgA-based combination by enzyme-linked immunosorbent assay as preferred screening method for nasopharyngeal carcinoma: a two-stage design with a preliminary performance study and a mass screening in southern China. Int J Cancer. 2012;131:406-16. https://doi. org/10.1002/ijc.26380.

28. Korte W. Changes of the coagulation and fibrinolysis system in malignancy: their possible impact on future diagnostic and therapeutic procedures. Clin Chem Lab Med. 2000;38:679-92. https://doi.org/10.1515/ CCLM.2000.099.

29. Blom JW, Doggen CJ, Osanto S, Rosendaal FR. Malignancies, prothrombotic mutations, and the risk of venous thrombosis. JAMA. 2005;293:71522. https://doi.org/10.1001/jama.293.6.715.

30. Zhang C, Jia Y, Jia Y, Zhang X, Li K. Prognostic and predictive value of plasma D-dimer levels in patients with small-cell lung cancer. Int J Clin Oncol. 2018;23:1070-5. https://doi.org/10.1007/s10147-018-1320-5.

31. Lin Y, Liu Z, Qiu Y, Zhang J, Wu H, Liang R, et al. Clinical significance of plasma D-dimer and fibrinogen in digestive cancer: a systematic review and meta-analysis. Eur J Surg Oncol. 2018;44:1494-503. https://doi.org/ 10.1016/j.ejso.2018.07.052.

32. Qu H, Huang Y, Zhao S, Zhou Y, Lv W. Prognostic value of Epstein-Barr virus DNA level for nasopharyngeal carcinoma: a meta-analysis of 8128 cases. Eur Arch Otorhinolaryngol. 2020;277(1):9-18. https://doi.org/10. 1007/s00405-019-05699-9.

33. Dawson CW, Port RJ, Young LS. The role of the EBV-encoded latent membrane proteins LMP1 and LMP2 in the pathogenesis of nasopharyngeal carcinoma (NPC). Semin Cancer Biol. 2012;22(2):144-53. https://doi.org/ 10.1016/j.semcancer.2012.01.004.

\section{Publisher's Note}

Springer Nature remains neutral with regard to jurisdictional claims in published maps and institutional affiliations.
Ready to submit your research? Choose BMC and benefit from:

- fast, convenient online submission

- thorough peer review by experienced researchers in your field

- rapid publication on acceptance

- support for research data, including large and complex data types

- gold Open Access which fosters wider collaboration and increased citations

- maximum visibility for your research: over $100 \mathrm{M}$ website views per year

At BMC, research is always in progress.

Learn more biomedcentral.com/submissions 